\title{
Self-determined motivation and academic buoyancy as predictors of achievement in normative settings
}

\author{
Görkem Aydın* (D) and Aikaterini Michou \\ Graduate School of Education, Bilkent University, Ankara, Turkey
}

Background. Academic buoyancy (Martin \& Marsh, 2006, Oxford Review of Education, 35, 353; 2008, Journal of School Psychology, 46, 53) is students' competence to respond effectively to academic daily setbacks and is considered an optimal characteristic of students' functioning related to achievement. From the self-determination theory perspective (Ryan \& Deci, 2017, American Psychologist, 55, 68), satisfaction of the need for autonomy, competence, and relatedness and autonomous forms of motivation relate to students' optimal functioning in schooling.

Aims. We investigated (I) whether students' end-of-course (T2) academic buoyancy in the normative environment of English preparatory programmes (EPP) is predicted by their beginning-of-course ( $\mathrm{TI})$ need satisfaction or frustration and autonomous or controlled motivation (i.e., high or low self-determined motivation), and (2) whether students' T2 academic buoyancy mediates the relation between students' TI selfdetermined motivation and final (T3) academic achievement.

Sample. In TI and T2, 267 students $\left(M_{\text {age }}=19.11, S D=1.28\right)$ attending three EPPs in Ankara, Turkey, participated in the study.

Method. A prospective design was used, data were collected through self-reports, and SEM was conducted to test the hypotheses.

Results. Students' TI need frustration negatively predicted TI autonomous motivation and positively predicted TI controlled motivation, which (respectively) positively and negatively predicted $\mathrm{T} 2$ academic buoyancy. $\mathrm{TI}$ need satisfaction related positively to $\mathrm{T} 2$ academic buoyancy. Finally, T2 academic buoyancy mediated the relation between students' need satisfaction and final achievement while controlled motivation was also negatively related to final achievement.

Conclusion. Students' high need satisfaction and low need frustration as well as high autonomous and low controlled motivation could support students' buoyancy and achievement in the normative settings of EPP.

Students who are accepted into English-speaking universities without English language proficiency usually follow an English preparatory programme (EPP) in order to achieve standard language skills. In these normative educational settings, some students smoothly progress from lower to higher levels of English by succeeding in several frequent

*Correspondence should be addressed to Görkem Aydın, Bilkent University, N Building 06800 Bilkent, Ankara, Turkey (email: gorkemaydin@bilkent.edu.tr). 
examinations, while others, who fail those examinations, repeat the same level. Repetition of levels means prolonged studies which result in either success in the English language proficiency examination or dropout accompanied by financial and psychological consequences for students and their parents. According to Martin and Marsh $(2006,2008)$, one of the capacities that could make students respond differently in such demanding educational situations is academic buoyancy.

Research has shown that when students are able to cope effectively with regular setbacks at school such as challenging assignments or failure in examinations, they function optimally and achieve better (Collie, Martin, Malmberg, Hall, \& Gins, 2015; Martin, 2014). We believe that, especially in normative educational settings such as EPPs, where students should meet the norms set by institutions irrespective of their personal attributes, the ability to 'float on academic water' seems very important for students to perform well. If students are not buoyant in the face of challenging assignments and examinations defined by standard language skills they should develop, they risk not being admitted into a university department. But what are the predictors of academic buoyancy?

Research indicates that students' academic buoyancy is predicted by the expectancy (e.g., self-efficacy and control beliefs) and the affective (e.g., anxiety) components of their motivation as well as their persistence in schoolwork (Martin, Colmar, Davey, \& Marsh, 2010). It has also been shown that academic buoyancy is predicted by students' achievement goals (Yu \& Martin, 2014), an aspect of the value component of motivation (Pintrich \& De Groot, 1990). However, the role of the self-determination component of students' motivation (to what extent they feel agents of their behaviour; Deci \& Ryan, 2000) in the prediction of academic buoyancy has not been investigated yet, preventing us from fully understanding why a student is more academically buoyant than another.

As it has been pointed out by self-determination theory (Deci \& Ryan, 2000; Ryan \& Deci, 2017), students' optimal cognitive and behavioural functioning (e.g., academic buoyancy) can also be energized by psychological needs such as a sense of self-governance as well as by autonomous (e.g., self-endorsed) motivation. We believe that, especially in normative settings where objectives are externally set, the degree to which students perceive their academic work as personally valuable and self-endorsed (e.g., autonomous motivation) or induced by others (e.g., controlled motivation) is a decisive predictor of academic buoyancy and achievement.

In an attempt, therefore, to better understand success and failure in normative educational settings, in the present prospective study, we investigated to what extent students' end-of-course (Time 2; T2) academic buoyancy in EPPs is predicted by their initial (Time 1; T1) self-determined motivation (operationalized as the degree of students' satisfaction of their psychological needs as well as their autonomous motivation) versus non-self-determined motivation (operationalized as the degree of students' need frustration of their psychological needs as well as their controlled motivation). We also investigated to what extent students' T2 academic buoyancy mediates the relation between students' T1 self-determined or non-self-determined motivation and final (Time 3; T3) academic achievement, which, as an indicator of success or failure, is the outcome of focus in our study.

\section{Academic buoyancy and motivation}

Academic buoyancy has been proposed by Martin and Marsh (2006, 2008, 2009) to describe students' competence to respond effectively to daily setbacks such as poor grades in examinations or pressuring deadlines. When students attain a high level of 
academic buoyancy and do not let negative academic experiences take control of their school lives, they cope more effectively with daily academic challenges. Therefore, students' academic buoyancy is an important factor to be considered, especially in normative educational settings where students should meet externally defined standards.

In prior research, academic buoyancy has been found to be predicted by components of students' motivation such as self-efficacy, planning, engagement (e.g., persistence, enjoyment, participation, aspirations and valuing), and anxiety and uncertain control (Martin, Colmar, Davey, \& Marsh, 2010; Martin \& Marsh, 2006, 2008). Prior research has shown that academic buoyancy is also related to achievement goals which, for Pintrich and De Groot (1990), are indicators of the value component of motivation. Yu and Martin (2014) found that mastery goals (e.g., the goal to learn as much as possible) and the personal best goal (e.g., the goal of self-referenced improvement) are positively related to middle school students' academic buoyancy.

It seems, therefore, that when students feel competent in schoolwork, have selfregulatory skills of planning and persistence, and endorse learning and self-improving goals, they are more likely to be able to overcome daily aversive situations at school. However, as research in the framework of SDT (Ryan \& Deci, 2017) has shown, students who are competent in schoolwork are not always willing to participate in school activities, especially when the school environment forces them to do so under normative situations. As well as self-efficacy and sense of control, students' volitional and selfendorsed participation in school activities is also important for optimal functioning at school (Deci \& Ryan, 2008; Ryan \& Deci, 2000; Vansteenkiste, Zhou, Lens, \& Soenens, 2005). This means that when students have internalized the values, norms, and beliefs of the educational context and are engaged in academic activities because they are enjoyable and interesting or important for their personal goals (autonomous motivation), they are more likely to be buoyant in academic setbacks. This is because the setbacks are part of what students like or find important to do and they are probably perceived as challenges. Indeed, in the sport context, autonomous motivation is positively associated with challenge appraisals and greater effort and persistence for a goal that becomes gradually difficult to attain (Ntoumanis et al., 2014). We expect the same pattern in the educational context by observing higher academic buoyancy for daily setbacks in students who are autonomously motivated. On the other hand, when students are engaged in academic activities for less internalized reasons such as to avoid trouble, please parents, or avoid feeling guilty (controlled motivation), they are more likely to be vulnerable in academic setbacks. This is because the setbacks are part of activities that others expect from them to do and they are probably perceived as threats by the students. Indeed, in the sport context, controlled motivation is positively associated with threat appraisals, high hopelessness and discouragement and low persistence for a goal that becomes increasingly difficult to attain (Ntoumanis et al., 2014). We expect the same pattern in the educational context by observing lower academic buoyancy for daily setbacks in students with controlled motivation. However, this assumption has not been investigated yet and what helps students to be buoyant has not been fully explained.

\section{Motivation from the self-determination theory perspective}

According to self-determination theory (Deci \& Ryan, 2000; Ryan \& Deci, 2017), when people satisfy three basic psychological needs (e.g., autonomy, competence, and relatedness), they experience growth and well-being. The need for autonomy refers to the experience of a volitional behaviour. The need for competence refers to the experience of 
effectiveness, and the need for relatedness refers to feeling closeness and connection in one's in-group interactions.

Satisfaction or frustration of the three needs determines one's quality of motivation (Ryan \& Deci, 2000). In the educational context, different types of motivation can be observed, depending on whether there is a need-supportive or need-thwarting environment. When students' psychological needs are frustrated, their performance in school work is instigated by external demands, rewards, threats (e.g., external regulation), or guilty feelings (e.g., introjected regulation; Bartholomew et al., 2018; Chen et al., 2015; Haerens, Aelterman, Vansteenkiste, Soenens, \& Van Petegem, 2015). In other words, they develop a controlled motivation. When students' psychological needs are satisfied, they develop an autonomous motivation (Kanat-Maymon, Benjamin, Stavsky, Shoshani, \& Roth, 2015; Milyavskaya \& Koestner, 2011; Ntoumanis, 2001, 2005). They are motivated in school activities by interest, by pleasure (e.g., intrinsic regulation), or by perceived personal importance in the activities (e.g., identified regulation).

In the context of learning English as a foreign language (EFL), it has also been found that need-supportive classrooms facilitate students' autonomous motivation (McEown, Noels \& Saumure, 2014; Noels, 2005, 2009). Moreover, Raižienè, Gabrialavičiūtè, Garckija, and Silinskas (2018), in an attempt to clarify the relation of each separate psychological need to students' quality of motivation, showed that satisfaction of each of the three psychological needs has a unique effect on students' autonomous motivation, while a balanced satisfaction of the three needs explains additional variance in students' autonomous motivation.

Furthermore, autonomous motivation is important to be developed in the educational context as it is positively related to engagement (Hafen et al., 2012; McEown, Noels, \& Saumure, 2014), persistence (Deci \& Ryan, 2008), adaptive coping and effort (Mouratidis \& Michou, 2011), high grades (Soenens \& Vansteenkiste, 2005), and high second language achievement (Joe, Hiver \& Al-Hoorie, 2017). Most of these positive correlates of autonomous motivation (e.g., engagement, persistence, and achievement) have also been found to be related to academic buoyancy (see Martin, 2014; Martin, Colmar, Davey, \& Marsh, 2010; Martin \& Marsh, 2006, 2008). We argue, therefore, that students' autonomous motivation will also be related to academic buoyancy. When students are engaged in an activity out of interest or to attain personal important goals (e.g., autonomously motivated), they are more likely to be competent to deal effectively with the challenges of the activity as the activity has personal meaning for them.

Controlled motivation, on the other hand, predicts a variety of undesirable outcomes such as dropout, maladaptive learning attitudes, ill-being (Vansteenkiste et al., 2005), less engagement (Ryan \& Deci, 2006), and low achievement (Soenens \& Vansteenkiste, 2005). Some of these negative outcomes of controlled motivation (e.g., low engagement and achievement) are also negatively related to academic buoyancy (see Martin, 2014; Martin \& Marsh, 2008). We argue, therefore, that students who are instigated by threats, rewards, or ego concerns (e.g., controlled motivation) are more likely to experience stress and feel less confident after getting a bad mark. That is, controlled motivation may hinder students from being competent to overcome daily academic setbacks. The quality of students' motivation seems to be related to students' academic buoyancy. Moreover, as quality of motivation is the result of need satisfaction or frustration, we argue that need satisfaction will also be related to buoyancy through autonomous versus controlled motivation. 


\section{The present research}

The present prospective study attempted to answer whether quality of motivation predicts high or low academic buoyancy and achievement in EPPs. We, therefore, investigated the relation of perceived need satisfaction (or frustration) to autonomous (or controlled) motivation at the beginning of a 2-month course (T1) in EPPs and, in sequence, their relation to subsequent (T2) academic buoyancy and, through it, to achievement in the 2-month course's final examination (T3).

Based on Raižienè et al. (2018) and Sheldon and Filak (2008), who found that satisfaction of need for autonomy, competence, and relatedness was positively related to autonomous motivation, we anticipated autonomous motivation to be positively predicted by need satisfaction and negatively predicted by need frustration. The opposite pattern of relations was hypothesized for controlled motivation (Hypothesis 1).

As research has shown that various motivational factors such as self-efficacy, planning, persistence, low anxiety, and low uncertain control (all correlates of autonomous motivation) positively predict students' academic buoyancy (Martin \& Marsh, 2006, 2008), we also anticipated that T1 autonomous and controlled motivation would positively and negatively relate to students' T2 academic buoyancy (Hypothesis 2a). We also hypothesized that T1 autonomous and controlled motivation would mediate the relation between $\mathrm{T} 1$ need satisfaction and frustration, and T2 academic buoyancy (Hypothesis 2b).

Finally, we hypothesized that students' T2 academic buoyancy would mediate the relation between students' T1 self-determined motivation (e.g., need satisfaction or frustration and autonomous or controlled motivation) and T3 academic achievement (Hypothesis 3), as Yun, Hiver, and Al-Hoorie (2018) have shown that academic buoyancy relates to achievement in the context of learning English as a foreign language. Our hypotheses are presented in Figure 1.

\section{Method}

\section{Participants and procedure}

The T1 survey was completed by 443 students, while the T2 survey was completed by 310 students from three EPPs in Ankara, Turkey. Among them, 267 students (56.9\% females; $M_{\text {age }}=19.1, S D=1.26$ ) participated in both $\mathrm{T} 1$ and $\mathrm{T} 2$. We selected two EPPs, one from a large-scale state and the other from a private university. We also selected an EPP from a small-scale private university. All three EPPs are English language medium institutions with the vast majority of students being Turkish. The students who participated in the study were selected according to the willingness of their teachers to provide class time to administer the survey. Two hundred and fifty-nine students were in their first year, and eight students were in their second year of the EPP. The distribution of students among the three programmes was, respectively, 120, 95, and 52 .

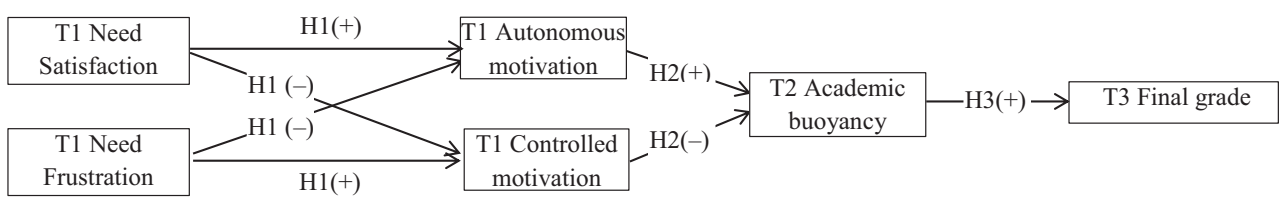

Figure I. The hypothesized model of the three needs' satisfaction or frustration as exogenous variables. 
After receiving the ethical approval from the University's Ethical Committee, the directors and instructors of the EPPs were informed about the procedure of the study. The T1 survey was administered by the instructors in normally scheduled classes in the second week of the English course of the third 8-week period in EPPs. The students, after consenting their participation, anonymously completed the T1 survey that assessed background variables, need satisfaction and frustration, and quality of motivation for that specific English course. The T2 survey, which assessed academic buoyancy in EPP, was conducted in the seventh week of the English course. To match T1 and T2 questionnaires, students indicated their ID code. Students' grades in the final course examination were provided by the EPPs. All the instruments were translated into Turkish by Turkish native speakers fluent in English and back translated by English native speakers fluent in Turkish. Discrepancies in the back translation were discussed among the Turkish and English translators to attain consent (Hambleton \& De Jong, 2003). Each item in the questionnaires was assessed in a five-point, Likert-type scale ranging from 1 (totally disagree) to 5 (totally agree).

\section{Measures}

\section{Background variables}

Students were asked to indicate their institution, gender, age, and number of courses they repeated, if any. An academic year in the participating EPPs includes four 8-week English courses. Students who fail in any of these courses repeat the course. Students being in the first year of their studies in EPP and in the third 8-week period could have repeated a maximum of three classes, while students in the second year could have repeated a maximum of seven classes. The number of repeated classes was converted into three and therefore ranged from zero to three in the final analyses.

\section{Need satisfaction and need frustration}

Students' need satisfaction and frustration in the EPP were assessed by the Basic Psychological Need Satisfaction and Frustration Scale (BPNSFS; Chen et al., 2015). Under the stem item 'In this EPP', twelve items assessed need satisfaction (four items for each need; need for autonomy, e.g., I feel a sense of choice and freedom in the things I undertake, $\alpha=.61$; need for competence, e.g., I feel confident that I can do things well, $\alpha=.75$; need for relatedness, e.g., I feel that the people I care about also care about me, $\alpha=.66$ ). Twelve items assessed need frustration (four items for each need; need for autonomy, e.g., Most of the things I do feel like 'I have to', $\alpha=.77$; need for competency, e.g., I have serious doubts about whether I can do things well, $\alpha=.70$; need for relatedness, e.g., I feel excluded from the group I want to belong to, $\alpha=.63$ ). A confirmatory factor analysis (CFA) loading each 4-item set to respective six latent factors yielded an acceptable fit: S-B $\chi(237, N=407)=390.249, p<.01, \mathrm{CFI}=.927$, SRMR $=.051$, RMSEA $=.040$ (90\%-CI: 0.042 to 0.055$)$.

\section{Quality of motivation}

Sixteen items from the Academic Self-Regulation Questionnaire (SRQ-A; Ryan \& Connell, 1989) were used to assess students' quality of motivation for their classwork in the course (external regulation, five items, e.g., Because that's the rule; introjected regulation, five 
items, e.g., Because I want the teacher to think I'm a good student; identified regulation, three items, e.g., Because I want to learn new things; intrinsic regulation, three items, e.g., Because it's fun).

A CFA for the hypothesized two-factor structure (autonomous and controlled motivation) yielded a poor fit. Therefore, items with factor loading $\leq .30$ were excluded (one external and two introjected regulation items) and correlated uniqueness (errors) between items of the same latent factor, according to suggestions in the modification indices, were included into the two-factor model while an identified item was allowed to load to the controlled motivation latent factor as well. The final factor structure consisted of 13 items. Two aggregated scores were computed for controlled (one external item and two introjected items were excluded; $\alpha=.74)$ and autonomous $(\alpha=.81)$ motivation.

\section{Academic buoyancy}

The four-item Academic Buoyancy Scale (Martin \& Marsh, 2008) was used to measure the ability to overcome daily academic adversities in EPP (e.g., I'm good at dealing with setbacks at school, $\alpha=.77)$. A CFA yielded the following acceptable fit: S- $B \chi$ (2, $N=301)=8.050, p<.01, \mathrm{CFI}=.976$, SRMR $=.022, \mathrm{RMSEA}=.100(90 \%-\mathrm{CI}: 0.034$ to $0.176)$.

\section{Final grades}

Students' final examination scores in the English course were collected from the participating EPPs. EEPs in Turkey follow the Common European Framework of Reference (CEFR) for learning, teaching, and assessing English. Therefore, final examinations in each of the five levels of CEFR (e.g., A1, A2, B1, B2, and C1) assess the same skills. The range of the scores was between 19.25 and 95.50 (out of 100), and their average was $66.92(S D=13.40)$. Standardized scores were computed for each separate EPP.

\section{Plan of analysis}

As preliminary analyses, Cronbach's alpha for each subscale was calculated and CFA to test the factor structure of all the measures was conducted using the $\mathrm{R}$ software with robust maximum likelihood estimation. The mean of each subscale was computed, and the descriptive statistics and bivariate correlations were checked using SPSS 20. We also examined gender and EPP differences through MANOVA as well as differences between students who participated only in T1 and students who participated in both T1 and T2.

In the main analyses, structural equation modelling (SEM) was conducted using $\mathrm{R}$ software (package Lavaan) to test the hypotheses. Two separate models were tested for need satisfaction and frustration as exogenous variables. This is because, when need satisfaction and frustration were included in the same model, the high correlation between them (e.g., $r=-.51$ ) yielded unexpected relations with the endogenous variables that are not justified by the correlation table. We first tested the measurement models with T1 need satisfaction (or alternatively T1 need frustration) as a composite latent factor by loading to them the corresponding 12 satisfaction and 12 frustration items. Accordingly, T1 autonomous motivation was identified by the six items of identified and intrinsic regulations and $\mathrm{T} 1$ controlled motivation by the seven items of introjected and external regulations. T2 academic buoyancy was identified by the four corresponding 
items while the standardized scores of students' final grade were used as an observed variable. We then tested the structural models, where the composite latent factor for need satisfaction (or frustration) predicted T1 autonomous (composite latent factor) and T1 controlled (composite latent factor) motivation, which in sequence predicted T2 academic buoyancy, which predicted T3 grades. All hypothesized relations were tested by including gender, age, EPP, and number of repeated classes as covariates. The significance of indirect effects in the models was examined by both the typical method of Lavaan and the bootstrap approach with 1,000 replications.

Assessment of the model fit was based on multiple fit indices. Values at or above .90 and .95 are acceptable for the comparative fit index (CFI; Bentler, 1990; Kline, 2005), a non-significant chi-square reflects a good model fit, values of .08 or lower can be considered acceptable for the root mean square error of approximation (RMSEA; Byrne, 2001; Steiger, 1990), and values at or $<.05$ reflect good fit for the standardized root mean square residual (SRMR; Hu \& Bentler, 1995) whereas the cut-off limit for SRMR could be .08 for adequate fit. The Satorra-Bentler (SB) scaling method (Satorra \& Bentler, 1994) was used in conjunction with robust maximum likelihood (MLM) estimation.

\section{Results}

\section{Preliminary analysis}

Descriptive statistics and bivariate correlations among the measured and background variables are displayed in Table 1. A MANOVA showed no significant differences, Wilk's $\Lambda=.972, F(13,380)=0.829, p=.630$, multivariate $\eta^{2}=.03$, between the students who participated only in T1 $(N=134)$ and students who participated in both T1 and T2 $(N=267)$. A MANOVA, however, showed significant gender and EPP differences in the measured variables, Wilk's $\Lambda=.829, F(12,243)=4.179, p=.000$, multivariate $\eta^{2}=.171$ for gender and Wilk's $\Lambda=.636, F(24,484)=5.12, p<.01$, multivariate $\eta^{2}=.20$ for EPPs. In the MANOVA of the EPPs, a follow-up analysis of variance (ANOVA) with Bonferroni correction showed that the number of repeated classes in one EPP differed significantly from the number of repeated classes in the other two EPPs $F(1$, $256)=38.607, p<.01, \eta^{2}=.23\left(M_{\mathrm{EPP} 1}=0.87, S D=0.79\right.$ vs. $M_{\mathrm{EPP} 2}=0.24, S D=0.57$ and vs. $\left.M_{\mathrm{EPP} 3}=0.06, S D=0.24\right)$. In addition, as it is shown in Table 1 , age significantly related to grades, and therefore, gender, EPP, age, and number of repeated classes were included as covariates in the subsequent analyses.

\section{Main analysis}

The two measurement models fitted the data: $\mathrm{S}-\mathrm{B} \chi^{2}(385, N=238)=499.154, p<.01$. $\mathrm{CFI}=.929, \quad$ SRMR $=.065, \quad$ RMSEA $=.035$ (90\%-CI: 0.026 to 0.043$) ; \quad \mathrm{S}-\mathrm{B} \chi^{2} \quad(377$, $N=235)=511.625, p<.01$. CFI $=.922$, SRMR $=.070$, RMSEA $=.039$ (90\%-CI: 0.031 to 0.047 ) for need satisfaction and frustration, respectively. The overall model fit was poor for the initial structural model of need satisfaction: S-B $\chi^{2}(491, N=229)=670.273$, $p<.01$. CFI $=.897$, SRMR $=.068$, RMSEA $=.040(90 \%-\mathrm{CI}: 0.033$ to 0.047$)$ and need frustration: $\mathrm{S}-\mathrm{B} \chi^{2} \quad(482, N=226)=665.543, p<.01 . \quad \mathrm{CFI}=.900, \quad$ SRMR $=.071$, RMSEA $=.041$ (90\%-CI: 0.034 to 0.048$)$. The modification indices suggested a direct path from controlled motivation to students' final grades as well as a direct path from need satisfaction to T2 academic buoyancy. Conceptually and theoretically, a poor quality of students' motivation (e.g., controlled motivation) is related to negative educational 


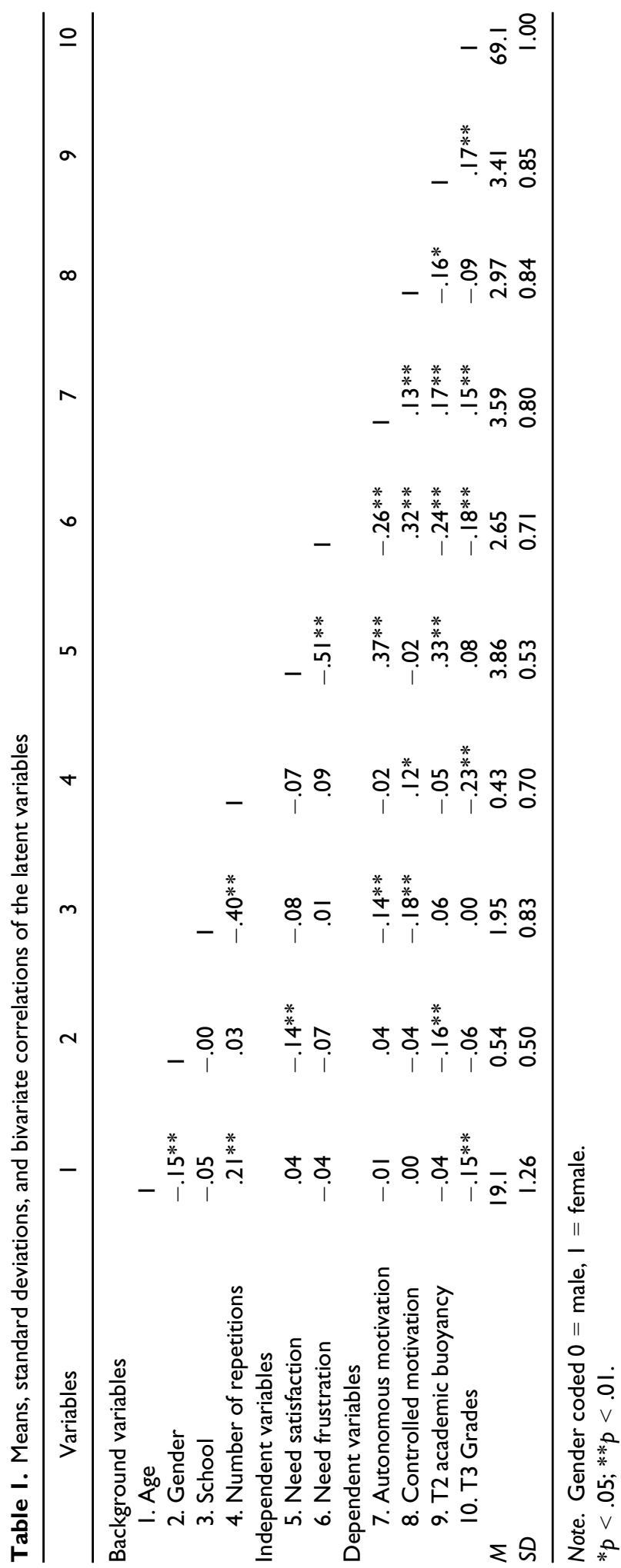


outcomes such as poor grades. Likewise, when students feel that their psychological needs are satisfied, they function optimally and are more likely to be buoyant in academic setbacks. Indeed, previous research has indicated that quality of motivation is a correlate of academic achievement (Soenens \& Vansteenkiste, 2005) and need satisfaction is a correlate of commitment to university studies (Davidson \& Beck, 2019) and engagement (e.g., Jang, Kim, \& Reeve, 2012) both concepts related to academic buoyancy. The suggested paths were, therefore, empirically and conceptually sound and thus were added to the models. Additionally, non-significant paths were removed from the two initial structural models. These modifications yielded the final structural model fit as follows: $\mathrm{S}-\mathrm{B} \chi^{2} \quad(489, \quad N=229)=652.017, \quad p<.01 . \quad \mathrm{CFI}=.906, \quad$ SRMR $=.065$, RMSEA $=.038(90 \%$-CI: 0.030 to 0.045$)$ and S-B $\chi^{2}(481, N=226)=657.820, p<.01$. $\mathrm{CFI}=.904, \mathrm{SRMR}=.070, \mathrm{RMSEA}=.040(90 \%$-CI: 0.033 to 0.047$)$ for the models of need satisfaction and frustration, respectively. The results of these two models that confirmed most of our hypothesis are depicted in Figures 2 and 3 while the correlations of the latent factors are presented in Tables 2 and 3.

The relation of need satisfaction or frustration to quality of motivation (Hypothesis I)

T1 need satisfaction was positively related to T1 autonomous motivation $(\beta=.57$, $p<.01$, see Figure 2), while T1 need frustration was negatively related to T1 autonomous motivation $(\beta=-.36, p<.01$, see Figure 3$)$ and positively related to T1 controlled motivation $(\beta=.37, p<.01)$. This finding supports our Hypothesis 1 and indicates that when students perceived that their need for autonomy was satisfied in EPP, they tended to

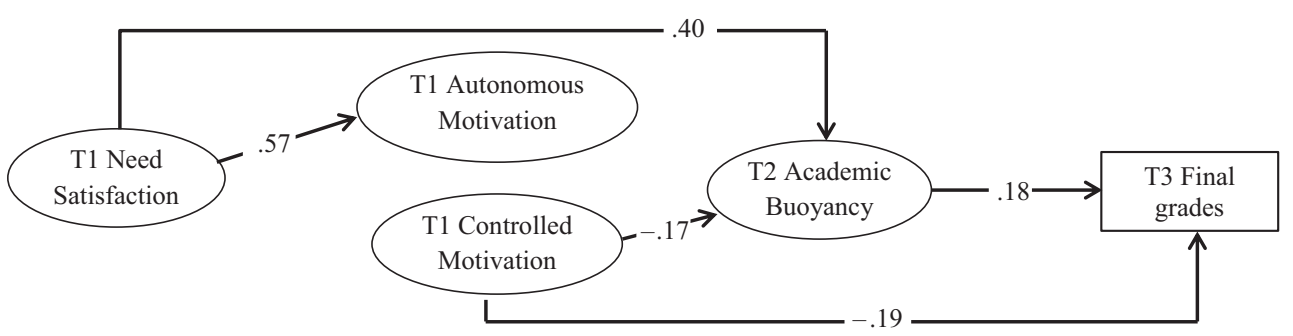

Figure 2. SEM for the mediating role of T2 academic buoyancy between TI self-determined motivation (e.g., need satisfaction and quality of motivation) and T3 achievement. Note. For coefficients $\leq \pm .19$, $p<.05$.

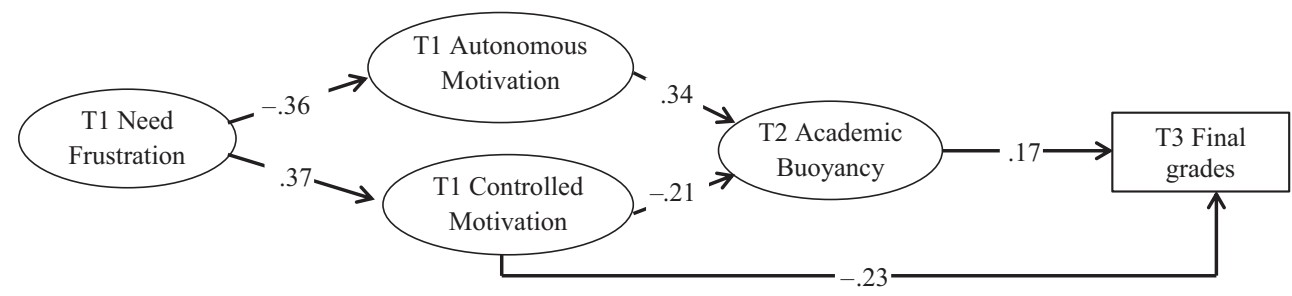

Figure 3. SEM for the mediating role of $\mathrm{T} 2$ academic buoyancy between $\mathrm{TI}$ self-determined motivation (e.g., need frustration and quality of motivation) and T3 achievement. Note. For coefficients $\leq \pm .2 \mathrm{I}$, $p<.05$. 
Table 2. Correlation of latent factors for the measurement model with need satisfaction

\begin{tabular}{lcllll}
\hline Variables & $\mathrm{I}$ & 2 & 3 & 4 & 5 \\
\hline $\begin{array}{l}\text { Independent variable } \\
\text { I. TI Need satisfaction }\end{array}$ & $\mathrm{I}$ & & & & \\
Dependent variables & & & & & \\
2. TI Autonomous motivation & $.53 * *$ & $\mathrm{I}$ & & \\
3. TI Controlled motivation & -.04 & .17 & $\mathrm{I}$ & \\
4. T2 Academic buoyancy & $.49 * *$ & $.32 * *$ & $-.20 *$ & $\mathrm{I}$ \\
5. Grades & .08 & .10 & $-.24 * *$ & $.25 * *$ \\
\hline
\end{tabular}

$*_{p}<.05 ; * p<.01$.

Table 3. Correlation of latent factors for the measurement model with need frustration

\begin{tabular}{|c|c|c|c|c|c|}
\hline Variables & 1 & 2 & 3 & 4 & 5 \\
\hline \multicolumn{6}{|l|}{ Independent variable } \\
\hline I. TI Need frustration & I & & & & \\
\hline \multicolumn{6}{|l|}{ Dependent variables } \\
\hline 2. TI Autonomous motivation & $-.38 * *$ & I & & & \\
\hline 3. TI Controlled motivation & $.33^{* *}$ & .14 & 1 & & \\
\hline 4. T2 Academic buoyancy & $-.25 *$ & $.26 *$ & -.19 & 1 & \\
\hline 5. Grades & $-.22 * *$ & .04 & $-.27^{* *}$ & $.24 * *$ & I \\
\hline
\end{tabular}

$* p<.05 ; * p<.01$.

have a good quality of motivation; however, when their perceived need frustration was high, they tended to have a poor quality of motivation.

The relation of self-determined motivation to academic buoyancy (Hypotheses $2 a$ and $2 b$ )

In support of our Hypothesis $2 \mathrm{a}$, controlled motivation was negatively related to $\mathrm{T} 2$ academic buoyancy $(\beta=-.17, p<.05, \beta=-.21, p<.05$, see Figures 2 and 3 , respectively) and autonomous motivation was positively related to T 2 academic buoyancy for the model of need frustration $(\beta=.34, p<.01)$. This demonstrates that students feel academically buoyant under the circumstance that they develop a good quality of motivation and specifically when they are involved in classroom tasks because they find them interesting or personally important. On the other hand, students feel less academically buoyant when they develop a poor quality of motivation, namely they are engaged in academic activities out of internal or external pressure.

In support of our Hypothesis $2 \mathrm{~b}$, a test of indirect effects showed that $\mathrm{T} 1$ autonomous and controlled motivation mediate the negative relation between T1 need frustration and T2 academic buoyancy $(\beta=-.12, p<.05, \beta=-.08, p<.05$, respectively, see Table 4$)$. Additionally, T1 need satisfaction related directly and positively to T2 academic buoyancy $(\beta=.40, p<.01)$.

The relation of T2 academic buoyancy and TI self-determined motivation to T3 grades (Hypothesis 3) Students' T2 academic buoyancy was positively related to final grades $(\beta=.18, p<.05$ in need satisfaction model, $\beta=.17, p<.05$ in need frustration model). Controlled 
Table 4. Results of the test of indirect effects - the two models for need satisfaction and need frustration as the predictors

\begin{tabular}{|c|c|c|c|c|c|}
\hline \multirow[b]{2}{*}{ Paths for the indirect effects } & \multicolumn{3}{|c|}{$\begin{array}{l}\text { Unstandardized parameter } \\
\text { estimates }\end{array}$} & \multirow{2}{*}{$\begin{array}{l}\text { Standardized } \\
\text { parameter } \\
\text { estimates } \\
\beta\end{array}$} & \multirow{2}{*}{$\begin{array}{l}95 \% \text { confidence } \\
\text { intervals } \\
\mathrm{Cl}\end{array}$} \\
\hline & Estimate & $S E$ & $Z$ score & & \\
\hline $\begin{array}{l}\text { TI Need satisfaction } \rightarrow \\
\text { T2 buoyancy } \rightarrow \text { Grades }\end{array}$ & .144 & .061 & 2.362 & $.07 \mid *$ & 0.012 to 0.492 \\
\hline $\begin{array}{l}\text { TI Need frustration } \rightarrow \\
\text { TI Autonomous motivation } \rightarrow \\
\text { T2 buoyancy }\end{array}$ & -.154 & .064 & -2.419 & $-.124 *$ & -0.029 to -0.530 \\
\hline $\begin{array}{l}\text { TI Need frustration } \rightarrow \\
\text { TI Controlled motivation } \rightarrow \\
\text { T2 buoyancy }\end{array}$ & -.095 & .049 & -1.964 & $-.077^{*}$ & -0.004 to -0.356 \\
\hline $\begin{array}{l}\text { T1 Autonomous motivation } \rightarrow \\
\text { T2 buoyancy } \rightarrow \text { Grades }\end{array}$ & .166 & .074 & 2.253 & $.057^{*}$ & 0.013 to $0.57 \mathrm{I}$ \\
\hline $\begin{array}{l}\text { TI Need frustration } \rightarrow \\
\text { TI controlled motivation } \rightarrow \\
\text { Grades }\end{array}$ &.$-|4|$ & .058 & -2.451 & $-.084 *$ & -0.022 to -0.486 \\
\hline
\end{tabular}

Note. The confidence intervals were calculated with the bootstrap method ( $n=1,000$ replications). $* p<.05$.

motivation was also negatively related to final grades $(\beta=-.19, p<.05$ in need satisfaction model, $\beta=-.23, p<.01$ in need frustration model). It seems that when students possess a high level of academic buoyancy in EPP, they perform better in English courses, and when students are instigated by controlled motivation in English classes, they do not perform so well.

A test of indirect effects in the model of need satisfaction (Figure 2) showed that academic buoyancy mediated the positive relation between T1 need satisfaction and T3 grades $(\beta=-.07, p<.05$, see Table 4$)$, supporting Hypothesis 3 . In the model of need frustration (Figure 3), T2 academic buoyancy mediated the positive relation between T1 autonomous motivation and T3 grades $(\beta=.06, p<.05)$. It is worthy also to note that T1 controlled motivation mediated the negative relation between T1 need frustration and T3 grades $(\beta=-.08, p<.05)$.

\section{Discussion}

In line with theory and research suggesting that satisfaction or frustration of basic psychological needs predicts students' quality of motivation (Deci \& Ryan, 2000) and that various motivational factors positively predict students' academic buoyancy (Martin \& Marsh, 2006, 2008), in the current study, we investigated to what extent students' end-ofcourse academic buoyancy in EPP is predicted by their initial self-determined motivation (operationalized as need satisfaction or frustration and quality of motivation). Secondly, consistent with prior research showing that academic buoyancy predicts academic achievement (Joe et al., 2017; Martin, 2014) and in an attempt to investigate predictors of achievement in normative educational settings, we examined whether students' end-ofcourse academic buoyancy mediated the relation between students' initial selfdetermined motivation and end-of-course achievement. 
According to our predictions, when students perceived high need satisfaction in the EPP, they were also highly autonomously motivated. Alternatively, when they perceived need frustration, the quality of their motivation was less autonomous and more controlled. Moreover, autonomous motivation and controlled motivation were mechanisms through which initial levels of need frustration in EPP were manifested to subsequent academic buoyancy. Interestingly enough, initial levels of need satisfaction and frustration in EPP were also directly related to subsequent academic buoyancy. Together, these two findings verify our initial argument that self-determined motivation (operationalized as need satisfaction and a sense of volition and personal causation, that is autonomous motivation) is also needed in order for students to navigate the academic setbacks.

Additionally, according to our predictions, high academic buoyancy at the end of the academic term was positively related to high final grades in the English course. Interestingly, apart from high academic buoyancy, low controlled motivation directly predicted high grades. Previous research in SDT has also shown that quality of motivation relates to academic achievement (Soenens \& Vansteenkiste, 2005). The present study showed that students' success in the normative settings of EPPs depended on both their quality of motivation and their ability to 'float on academic water'. Moreover, students' success in EPPs depended on need satisfaction as it was positively (and need frustration negatively) related to final grades through academic buoyancy (or controlled motivation).

The findings of the present study suggest that EPPs need to create a need-supportive environment in order for students to be engaged in learning activities for self-endorsed versus imposed-by-others reasons and be buoyant in adverse academic situations. In EPPs, teachers need to show their students that they have choices in the way they will approach the course activities and a voice about the content or the conditions of the learning process (satisfaction of need for autonomy; Reeve, 2006). They also need to provide informational feedback and a rationale for the usefulness of the course activities (satisfaction of need for competence; Assor, Kaplan, \& Roth, 2002; Mouratidis, Vansteenkiste, Lens, \& Sideridis, 2008). Moreover, students need to feel that their teacher is available to support and listen to them (satisfaction of need for relatedness; Reeve, 2006). Under such need-supportive conditions, less need frustration will be perceived by the students and the potential of a good quality of motivation and high academic buoyancy will be increased, preventing students from failure in examinations and repetition of courses. Especially in the Turkish context, where EPPs tend to fail to address Turkish students' low English proficiency level and low motivation (British, 2015), training English teachers of the EPPs to be need-supportive seems to be important for students' academic buoyancy and success.

\section{Limitations and future directions}

Our study has a number of limitations to be taken into consideration when discussing findings. The first is that the data were self-reported and therefore students might have given desirable answers while responding to the items or focused only on their recent experience. Also, no causality among studied variables was investigated which can only be inferred by experimental studies. Second, autonomous motivation was operationalized as the mean of intrinsic (e.g., it is fun) and identified (e.g., it is important) behavioural regulation. However, according to SDT, autonomous motivation consists of integrated regulation as well (e.g., behavioural regulation through personal values and self-identity), which was not assessed in this study. Future research could investigate to what extent inclusion of integrated regulation would strengthen the relation of autonomous 
motivation to academic buoyancy. Third, data were collected from three universities in Turkey and results may not generalize to other contexts. Fourth, by having a small number of students from each participating class, class-level differences in students' reports were not considered. Future research might therefore look to conduct multilevel analyses to formally assess class-level effects. Finally, this prospective study was held in 2-month courses and the time between initial and final surveys was only 5 weeks. There would be merit in assessing academic buoyancy and its predictors and outcomes in a longer period of time as well as through repeated measures (e.g., diary study), if possible, before and after specific academic setbacks. Such a design would therefore enable researchers to show the dynamic relationships among the studied variables.

\section{Conclusion}

The present prospective study explored why some students are more buoyant and achieve better than others in the normative settings of EPPs by taking into consideration the degree of students' perceived need satisfaction and frustration as well as the selfendorsed versus imposed-by-others reasons for engagement in learning activities. The findings suggest that high perceived need satisfaction and low perceived need frustration as well as high self-endorsed motivation and low imposed-by-others motivation are needed in order for students to effectively navigate the academic setbacks of EPPs. Regarding achievement, the present study found that high perceived need satisfaction and academic buoyancy as well as low perceived need frustration and imposed-by-others motivation are important for high final grades in the EPP courses. EPPs need to consider to what extent students' psychological needs are satisfied to facilitate them to develop a good quality of motivation and academic buoyancy and achieve high grades.

\section{References}

Assor, A., Kaplan, H., \& Roth, G. (2002). Choice is good, but relevance is excellent: Autonomyenhancing and suppressing teacher behaviours predicting students' engagement in schoolwork. British Journal of Educational Psychology, 72, 261-278. https://doi.org/10.1348/ 000709902158883

Bartholomew, K. J., Ntoumanis, N., Mouratidis, A., Katartzi, E., Thøgersen-Ntoumani, C., \& Vlachopoulos, S. (2018). Beware of your teaching style: A school-year long investigation of controlling teaching and student motivational experiences. Learning and Instruction, 53, 50 63. https://doi.org/10.1016/j.learninstruc.2017.07.006

Bentler, P. M. (1990). Comparative fit indexes in structural models. Psychological Bulletin, 107, 238-246. https://doi.org/10.1037/0033-2909.107.2.238

British, C. (2015). The state of English in Higher Education in Turkey: A baseline study. Retrieved from http://www.britishcouncil.org.tr/sites/default/files/he_baseline_study_book_web_son. pdf

Byrne, B. M. (2001). Structural equation modelling with AMOS, EQS, and LISREL: Comparative approaches to testing for the factorial validity of a measuring instrument. International Journal of Testing, 1, 55-86. https://doi.org/10.1207/S15327574IJT0101_4

Chen, B., Vansteenkiste, M., Beyers, W., Boone, L., Deci, E. L., Van der Kaap-Deeder, J., . . Ryan, R. M. (2015). Basic psychological need satisfaction, need frustration, and need strength across four cultures. Motivation and Emotion, 39, 216-236. https://doi.org/10.1007/s11031-014-9450-1

Collie, R. J., Martin, A. J., Malmberg, L. E., Hall, J., \& Ginns, P. (2015). Academic buoyancy, student's achievement, and the linking role of control: A cross-lagged analysis of high school students. British Journal of Educational Psychology, 85, 113-130. https://doi.org/10.1111/bjep.12066 
Davidson, W., \& Beck, H. P. (2019). Analyzing the commitment of college students using a brief, contextualized measure of need satisfaction from the perspective of Self-Determination Theory. Psychological Reports, 122, 1145-1166. https://doi.org/10.1177/0033294118769452

Deci, E. L., \& Ryan, R. M. (2000). The "what" and "why" of goal pursuits: Human needs and the selfdetermination of behavior. Psychological Inquiry, 11, 227-268. https://doi.org/10.1207/ S15327965PLI1104_01

Deci, E. L., \& Ryan, R. M. (2008). Self-determination theory: A macro theory of human motivation, development, and health. Canadian Psychology/Psychologie canadienne, 49, 182-185. https://doi.org/10.1037/a0012801

Haerens, L., Aelterman, N., Vansteenkiste, M., Soenens, B., \& Van Petegem, S. (2015). Do perceived autonomy-supportive and controlling teaching relate to physical education students' motivational experiences through unique pathways? Distinguishing between the bright and dark side of motivation. Psychology of Sport and Exercise, 16, 26-36. https://doi.org/10.1016/j. psychsport.2014.08.013

Hafen, C. A., Allen, J. P., Mikami, A. Y., Gregory, A., Hamre, B., \& Pianta, R. C. (2012). The pivotal role of adolescent autonomy in secondary school classrooms. Journal of Youth and Adolescence, 41, 245-255. https://doi.org/10.1007/s10964-011-9739-2

Hambleton, R. K., \& De Jong, J. H. A. L. (2003). Advances in translating and adapting educational and psychological tests. Language Testing, 20, 127-134. https://doi.org/10.1191/ $02655322031 \mathrm{t} 247 \mathrm{xx}$

Hu, L. T., \& Bentler, P. M. (1995). Evaluating model fit. In R. H. Hoyle (Ed.), Structural equation modeling: Concepts, issues, and applications (pp. 76-99). Thousand Oaks, CA: Sage.

Jang, H., Kim, E., \& Reeve, J. (2012). Longitudinal test of self-determination theory's motivation mediation model in a naturally occurring classroom context. Journal of Educational Psychology, 104, 1175-1188. https://doi.org/10.1037/a0028089

Joe, H. K., Hiver, P., \& Al-Hoorie, A. H. (2017). Classroom social climate, self-determined motivation, willingness to communicate, and achievement: A study of structural relationships in instructed second language settings. Learning and Individual Differences, 53, 133-144. https://doi.org/ 10.1016/j.lindif.2016.11.005

Kanat-Maymon, Y., Benjamin, M., Stavsky, A., Shoshani, A., \& Roth, G. (2015). The role of basic need fulfilment in academic dishonesty: A self-determination theory perspective. Contemporary Educational Psychology, 43, 1-9. https://doi.org/10.1016/j.cedpsych.2015.08.002

Kline, R. (2005). Principles and practice of structural equation modelling (2nd ed.). New York, NY: Guilford Press.

Martin, A. J. (2014). Academic buoyancy and academic outcomes: Towards a further understanding of students with attention-deficit/hyperactivity disorder (ADHD), students without ADHD, and academic buoyancy itself. British Journal of Educational Psychology, 84, 86-107. https://doi. org/10.1111/bjep.12007

Martin, A. J., Colmar, S. H., Davey, L. A., \& Marsh, H. W. (2010). Longitudinal modelling of academic buoyancy and motivation: Do the 5Cs hold up over time? British Journal of Educational Psychology, 80, 473-496. https://doi.org/10.1348/000709910X486376

Martin, A. J., \& Marsh, H. W. (2006). Academic resilience and its psychological and educational correlates: A construct validity approach. Psychology in the Schools, 43, 267-281. https://doi. org/10.1002/pits.20149

Martin, A. J., \& Marsh, H. W. (2008). Academic buoyancy: Towards an understanding of students' everyday academic resilience. Journal of School Psychology, 46, 53-83. https://doi.org/10. 1016/j.jsp.2007.01.002

Martin, A. J., \& Marsh, H. W. (2009). Academic resilience and academic buoyancy: Multidimensional and hierarchical conceptual framing of causes, correlates and cognate constructs. Oxford Review of Education, 35, 353-370. https://doi.org/10.1080/03054980902934639

McEown, M. S., Noels, K. A., \& Saumure, K. D. (2014). Students' self-determined and integrative orientations and teachers' motivational support in a Japanese as a foreign language context. System, 45, 227-241. https://doi.org/10.1016/j.system.2014.06.001 
Milyavskaya, M., \& Koestner, R. (2011). Psychological needs, motivation, and well-being: A test of self-determination theory across multiple domains. Personality and Individual Differences, 50 , 387-391. https://doi.org/10.1016/j.paid.2010.10.029

Mouratidis, A., \& Michou, A. (2011). Perfectionism, self-determined motivation, and coping among adolescent athletes. Psychology of Sport and Exercise, 12, 355-367. https://doi.org/10.1016/j. psychsport.2011.03.006

Mouratidis, A., Vansteenkiste, M., Lens, W., \& Sideridis, G. (2008). The motivating role of positive feedback in sport and physical education: Evidence for a motivational model. Journal of Sport and Exercise Psychology, 30, 240-268. https://doi.org/10.1123/jsep.30.2.24

Noels, K. A. (2005). Orientations to learning German: Heritage language learning and motivational substrates. The Canadian Modern Language Review/La revue canadienne des langues vivantes, 62, 285-312. https://doi.org/10.1353/cml.2006.0007

Noels, K. A. (2009). The internalisation of language learning into the self and social identity. In Z. Dornyei \& E. Ushioda (Eds.), Motivation, language identity and the L2 self (pp. 295-313). Bristol, UK: Multilingual Matters.

Ntoumanis, N. (2001). A self-determination approach to the understanding of motivation in physical education. British Journal of Educational Psychology, 71, 225-242. https://doi.org/10.1348/ 000709901158497

Ntoumanis, N. (2005). A prospective study of participation in optional school physical education using a self-determination theory framework. Journal of Educational Psychology, 97, 444-453. https://doi.org/10.1037/0022-0663.97.3.444

Ntoumanis, N., Healy, L. C., Sedikides, C., Duda, J., Stewart, B., Smith, A., \& Bond, J. (2014). When the going gets tough: The "why" of goal striving matters. Journal of Personality, 82, 225-236. https://doi.org/10.1111/jopy.12047

Pintrich, P. R., \& De Groot, E. V. (1990). Motivational and self-regulated learning components of classroom academic performance. Journal of Educational Psychology, 82, 33-40. https://doi. org/10.1037/0022-0663.82.1.33

Raižienè, S., Gabrialavičiūtè, I., Garckija, R., \& Silinskas, G. (2018). Satisfaction of basic psychological needs and autonomous motivation in school context: A test of additive, synergistic, and balance hypotheses. Croatian Journal of Education, 20, 399-429. https://doi.org/10.15516/cje.v20i2. 2752

Reeve, J. (2006). Teachers as facilitators: What autonomy-supportive teachers do and why their students benefit. Elementary School Journal, 106, 225-236. https://doi.org/10.1086/501484

Ryan, R. M., \& Connell, J. P. (1989). Perceived locus of causality and internalization: Examining reasons for acting in two domains. Journal of Personality and Social psychology, 57, 749-761. https://doi.org/10.1037/0022-3514.57.5.749

Ryan, R. M., \& Deci, E. L. (2000). Self-determination theory and the facilitation of intrinsic motivation, social development, and well-being. American Psychologist, 55, 68-78. https://doi. org/10.1037//0003-066X.55.1.68

Ryan, R. M., \& Deci, E. L. (2006). Self-regulation and the problem of human autonomy: Does psychology need choice, self-determination, and will? Journal of Personality, 74, 1557-1586. https://doi.org/10.1111/j.1467-6494.2006.00420.x

Ryan, R. M., \& Deci, E. L. (2017). Self-determination theory: Basic psychological needs in motivation, development, and wellness. New York, NY: Guilford Publications.

Satorra, A., \& Bentler, P. M. (1994). Corrections to test statistics and standard errors in covariance structure analysis. In A. von Eye \& C. C. Clogg (Eds.), Latent variables analysis: Applications for developmental research (pp. 399-419). Thousand Oaks, CA: Sage.

Sheldon, K. M., \& Filak, V. (2008). Manipulating autonomy, competence, and relatedness support in a game-learning context: New evidence that all three needs matter. British Journal of Social Psychology, 47, 267-283. https://doi.org/10.1348/014466607X238797

Soenens, B., \& Vansteenkiste, M. (2005). Antecedents and outcomes of self-determination in 3 life domains: The role of parents' and teachers' autonomy support. Journal of Youth and Adolescence, 34, 589-604. https://doi.org/10.1007/s10964-005-8948-y 
Steiger, J. H. (1990). Structural model evaluation and modification: An interval estimation approach. Multivariate Behavioral Research, 25, 173-180. https://doi.org/10.1207/s15327906mb r2502_4

Vansteenkiste, M., Zhou, M., Lens, W., \& Soenens, B. (2005). Experiences of autonomy and control among Chinese learners: Vitalizing or Immobilizing? Journal of Educational Psychology, 97, 468-483. https://doi.org/10.1037/0022-0663.97.3.468

Yu, K., \& Martin, A. J. (2014). Personal best (PB) and 'classic' achievement goals in the Chinese context: Their role in predicting academic motivation, engagement and buoyancy. Educational Psychology, 34, 635-658. https://doi.org/10.1080/01443410.2014.895297

Yun, S., Hiver, P., \& Al-Hoorie, A. H. (2018). Academic buoyancy: Exploring learners' everyday resilience in the language classroom. Studies in Second Language Acquisition, 40, 805-830. https://doi.org/10.1017/S0272263118000037

Received 19 July 2018; revised version received 23 November 2019 